\title{
Correlation of Obstetric Care Facility Density with Standard Emergency Obstetric and Neonatal Care Indicators in Tanzania Mainland
}

\author{
Projestine Muganyizi ${ }^{1, ~ *}$, Edward Maswanya ${ }^{2}$, Stella Kilima $^{2}$, Grades Stanley $^{2}$, Julius Massaga ${ }^{2}$, \\ Victor Bakengesa ${ }^{3}$ \\ ${ }^{1}$ Department of Obstetrics and Gynecology, Muhimbili University of Health and Allied Sciences, Dar es Salaam, Tanzania \\ ${ }^{2}$ National Institute for Medical Research, Dar es Salaam, Tanzania \\ ${ }^{3}$ Ministry of Health Community Development Gender Elderly and Children, Dar es Salaam, Tanzania
}

\section{Email address:}

promuga@yahoo.com (P. Muganyizi), edward19631@hotmail.com (E. Maswanya), stellakilima7@gmail.com (S. Kilima), gradesstanley@gmail.com (G. Stanley),jjmasaga@gmail.com (J. Massaga), vkrbaken@yahoo.com (V. Bakengesa)

${ }^{*}$ Corresponding author

\section{To cite this article:}

Projestine Muganyizi, Edward Maswanya, Stella Kilima, Grades Stanley, Julius Massaga, Victor Bakengesa. Correlation of Obstetric Care Facility Density with Standard Emergency Obstetric and Neonatal Care Indicators in Tanzania Mainland. Journal of Gynecology and Obstetrics. Vol. 5, No. 5, 2017, pp. 60-68. doi: 10.11648/j.jgo.20170505.12

Received: July 31, 2017; Accepted: August 15, 2017; Published: September 6, 2017

\begin{abstract}
Tanzania's Primary Health Services Development Program (PHSDP) started in 2007 with the aim to establish and staff an additional 5162 dispensaries, 2074 health centres and 8 district hospitals by 2017 which would implicitly increase obstetric care facility density. However, currently obstetric care facility density is not a standard Emergency Obstetric and Neonatal Care (EmONC) indicator and data on its correlation with the standard EmONC indicators is scanty. In 2015 a crosssectional survey of all hospitals, health centres and a random sample of dispensaries providing delivery services in all the 25 regions of Tanzania Mainland was conducted whereby the presence of EmONC functions in past 3 months was assessed using a standard tool. Where necessary, population data were based on the 2012 National housing and population Census and the 2010 Tanzania Demographic Health Survey (TDHS). Data were analyzed using IBM SPSS version 20 and STATA. Spatial Mapping was done using a calibrated Geographic Positioning System (GPS) Essential Software for Android and coordinates represented on digitalized map with Arc Geographic Information System (GIS). Ethical approval was granted by the Ethical Clearance Committee of Medical Research Council [MRCC], National Institute for Medical research. Of the confirmed 5207 obstetric care facilities $2405(46.2 \%)$ were surveyed including 35.3\% of all dispensaries. National Obstetric care facility density was 68/500,000 population, 7/500,000 of them provided all the 7 Basic Emergency Obstretic and Neonatal Care (BEmONC) functions in past 3 months. Among all the regions, $40 \%$ had attained or exceeded the international benchmark for EmONC facilities per 500,000 population. Institutional delivery rate was $79 \%$ and overall Caesarean Section rate was $5.6 \%$. Improved obstetric care facility density was strongly correlated with improved institutional delivery; Caesarean section rate and met need for EmONC but not the quality of case management. In conclusion obstetric care facility density is well correlated with other standard EmONC indicators.
\end{abstract}

Keywords: Emergency Obstetric Care, Neonatal Care, Obstetric Care Facility Density, Indicator, Correlation, Tanzania

\section{Introduction}

Improving accessibility, quality and utilization of Emergency obstetric and neonatal care (EmONC) services reduces maternal and neonatal mortality and morbidity.
Evidence to support the usefulness of EmONC interventions in averting maternal mortality is overwhelming although mostly emanating from quasi-experimental, observational and ecological designs [1]. Interventions to reduce maternal and neonatal mortality need strong indicators to be able to 
inform the progress, needs and overall monitoring of implementation. Since 1991 international indicators have been developed, revised and widely used under EmONC framework in programmes aiming at reducing maternal and neonatal mortality [2-10]. Standard EmONC indicators include the number of basic emergency obstetric and neonatal care (BEmONC) and comprehensive emergency obstetric and neonatal care (CEmONC) facilities as measured per 500,000 population; rate of EmONC institutional births; Met need for EmONC; population Caesarean section rate, direct and indirect case fatality rate and intrapartum and very early neonatal death rates [3, 4, 11-13]. Despite the wide application of the standard EmONC indicators, there are scanty published studies to describe the extent to which those indicators correlate with each other and with other program outcomes [9].

Tanzania has one of the highest maternal mortality ratio, estimated at 556/100,000 live births. In the past two decades there have been increased investments in health sector by the government and development partners. Among them the Primary Health Services Development Program (PHSDP) was introduced in 2007 with the aim to establish and staff an additional 5162 dispensaries, 2074 health centres and 8 district hospitals by 2017. A successful PHSDP would lead to having a dispensary at every village, a Health Centre at every ward and a District Hospital at every District [14]. This strategy would be expected to increase obstetric care facility density (OCFD). Nevertheless, increased OCFD is currently not considered one of EmONC indicators and its correlation with the standard indicators remains undetermined. The purpose of this study was to establish current OCFD in the 25 regions of Tanzania Mainland [henceforth termed as facility density], the status of standard EmONC indicators in Tanzania Mainland and to determine the correlation between OCFD and standard EmONC indicators. The results of this study are expected to inform policy makers, program managers and researchers on the current EmONC status in Tanzania and their correlation with OCFD.

\section{Materials and Methods}

This study was conducted in 2015 in all the 25 regions of Mainland Tanzania. An exhaustive list of 5207 obstetric care facilities was generated using data from the Ministry of Health Community Development Gender and Elderly and updates from the District Health Management Teams (DHMTs) in all the 110 district councils. It was agreed $a$ priori to survey all obstetric care hospitals and health centres. In addition, 10 randomly selected dispensaries from each district council were added to make up a total of 2405 (46.2\%) representative obstetric care facilities from which our data emanate. Multiple data sources were used, including interviews with facility Managers, interviews with healthcare workers, direct observations and review of records. In order to effectively address the study objectives, some extra demographic data were needed from recent (not older than 5 years) and reliable sources in compliance to international guidelines (WHO, UNFPA, UNICEF, and AMDD, 2009). For the purpose of this survey, additional information based on the National population and Housing Census of 2012 was officially sought from the National Bureau of Statistics (NBS). This information included local population figures and crude birth rates (CBR). Field data were collected using a standard EmONC data collection tool which was modified to include locally relevant indicators[10]. The EmONC tool has been extensively used to collect such data and is internationally accepted [8, 10, 15-18]. All field data were directly entered in an electronic tool and promptly sent online along with the facility's Global Positioning System (GPS) location. A total of 280 data collectors were involved mostly junior doctors and professional nurses with experience in collection of similar data according to the National Institute for Medical Research (NIMR) database. Data collectors received refresher training on ethical issues and the practice of data collection using the electronic questionnaire and GPS. The study was ethically approved by the Ethical Clearance Committee of Medical Research Council (MRCC), National Institute for Medical Research (NIMR) of the Ministry of Health, Community Development, Gender, Elderly and Children.

\subsection{EmONC Indicators}

Obstetric care facilities were defined as all facilities that provide delivery service. EmONC indicators were determined according to international guidelines[10]. EmONC services were classified as either BEmONC (which include the provision of injectable antibiotics, uterotonics, anticonvulsants and conducting manual removal of placenta, evacuation of uterus, assisted vaginal delivery and basic neonatal resuscitation with bag and mask.) or CEmONC services if blood transfusion and Cesarean section functions are provided in addition to the $7 \mathrm{BEmONC}$ functions. Based on this classification, BEmONC and CEmONC facilities were defined by virtue of their provision of the respective full set of functions in the past 3 months. Two indicators emanated from facility's EmONC status and were defined by the minimum number of EmONC facilities per 500, 000 population (ideally at least 5) and minimum number of Comprehensive CEmONC per 500,000 population (ideally should there be at least 1 among facilities that have provided a full set of BEmONC functions in past 3 months). Other indicators were the proportion of all births in EmONC facilities, Met need for EmONC, Cesarean section rate as a proportion of all births, direct obstetric case fatality rate (CFR) and the proportion of all maternal deaths due to indirect causes. In this study, the estimation of all births was calculated using regional and National level Crude Birth Rates (NBS, 2012). Met need for EmONC was defined as the proportion of all direct obstetric complications that were actually treated in obstetric care facilities [9, 10]. In calculating the Met Need, it was assumed that $15 \%$ of pregnant women develop severe direct obstetric complications $[1,9,19,20]$. Institutional delivery and institutional deaths refer to the proportion of all births that 
occurred in obstetric care facilities and all deaths in obstetric care facilities per 100,000 facility deliveries respectively. Annual Cesarean section rate was calculated as percentage of all births in a year that was delivered by Cesarean section. In this study intrapartum and very early neonatal death rates were not estimated due to incompleteness of data.

\subsection{Data Analysis}

Data were downloaded in Excel format and transferred into IBM SPSS version 20 and STATA programs for analysis. Spatial Mapping was done using a calibrated GPS Essential Software for Android and coordinates represented on digitalized map with Arc GIS software. For the purpose of current analysis, delivery in all obstetric care facilities as a proportion of all annual deliveries is referred to as institutional delivery and the annual direct and indirect causes of maternal deaths were combined and calculated as a proportion of 100,000 institutional deliveries to define institutional deaths since these two were considered relevant local indicators. Moreover, the number of Obstetric care facilities per 500,000 population (OCFD) was added as an important local indicator since the government has embarked on improved number of obstetric care facilities per population under the PHSDP which was introduced in 2007. Since data from dispensaries were not self weighted, all population based data were weighted. In the calculation of weights considerations were taken for the total number of facilities in the sampling frame for each level of facility in the country and the corresponding number of the initially sampled facilities. In the next step, field reports regarding the existed and accessed facilities for each level were considered. This information led to the calculation of corrected total number of facilities in the country and the corresponding corrected sample for each level of health facility. Weights were then calculated at each level of facilities by dividing the corrected total number of facilities by the corrected sample.
Weights were then used as inflating factors where necessary.

\subsection{Correlation Coefficient}

A region was the unit of analysis. Normality for all data variables was determined using the Shapiro-Wilk W test. Institutional delivery, OCFD, number of EmONC per 500,000 and Met need for EmONC were passed by this test. Scatter plots with 25 points and a fitted trend line were then created for all important pairs of indicators to determine the coefficient of determination $\left(\mathrm{R}^{2}\right)$. Additional significant linear trends were noted for the plots involving Cesarean section $\left(\mathrm{R}^{2}\right.$ range, 0.150-0.255) and plots involving institutional deaths $\left(\mathrm{R}^{2}\right.$ range, 0.207-0.505). These two indicators were added to the variables that passed ShapiroWilk $\mathrm{W}$ test. The correlation for relevant pairs of variables was determined by calculating Pearson Correlation coefficient (r) and p-values. Pearson's correlation coefficient (r) was interpreted based on absolute values of $\mathrm{r}$ as weak $=$ $0.1<\mathrm{r} \geq 0.3$, moderate $=0.3<\mathrm{r}>0.5$ and strong $=0.5-1.0$ inclusive[21].

\section{Results}

In total 2405 obstetric care facilities equal to $46.2 \%$ of all the 5207 obstetric care facilities in the country were surveyed including all health centres, all hospitals and $35.3 \%$ of the dispensaries in 25 regions. Overall $10.4 \%$ of the study sample facilities had provided all the seven BEmONC functions in the past 3 months including $100(41.2 \%)$ out of 243 hospitals, $83(13.0 \%)$ health centres out of 637 and 68 (4.5\%) of the 1525 dispensaries. When all 5207 obstetric care facilities were considered and weighted data for dispensaries calculated, only $7.0 \%$ of all obstetric care facilities in the country had provided all the 7 Basic functions in the past 3 months. The availability of individual EmONC functions in the past 3 months is shown in Table 1.

Table 1. Proportion of facilities that performed each signal function in the past three months.

\begin{tabular}{|c|c|c|c|c|c|c|}
\hline Signal function & $\begin{array}{l}\text { All } \\
(n=2405)\end{array}$ & $\begin{array}{l}\text { Hospitals } \\
(n=243)\end{array}$ & $\begin{array}{l}\text { Health Centres } \\
(n=637)\end{array}$ & $\begin{array}{l}\text { Dispensaries } \\
(n=1525)\end{array}$ & $\begin{array}{l}\text { Public } \\
(n=1980)\end{array}$ & Private $(n=425)$ \\
\hline \multicolumn{7}{|l|}{ Basic EmONC signal functions } \\
\hline Parenteral antibiotics & 71.4 & 86.8 & 79.9 & 65.3 & 70.3 & 76.5 \\
\hline Uterotonics & 96.8 & 97.9 & 96.9 & 96.6 & 96.8 & 96.9 \\
\hline Manual removal of placenta & 52.8 & 80.7 & 63 & 44.1 & 52.3 & 55.1 \\
\hline Parenteral anticonvulsants & 52.3 & 79.4 & 66.6 & 42 & 50.9 & 58.6 \\
\hline Neonatal resuscitation & 78.8 & 91.4 & 85.1 & 74.2 & 77.5 & 84.9 \\
\hline Assisted vaginal delivery & 17.2 & 52.3 & 22 & 9.7 & 14.8 & 28.5 \\
\hline \multicolumn{7}{|c|}{ Additional comprehensive EmONC signal functions* } \\
\hline Cesarean delivery & 31.9 & 76.1 & 15.1 & - & 24.6 & 46.7 \\
\hline Blood transfusion & 29.9 & 74.1 & 13.0 & - & 23.4 & 43.0 \\
\hline
\end{tabular}

*Only hospitals and health centres were included in the denominator since dispensaries are not eligible for CEmONC functions

Table 1 summarizes the provision of EmONC functions in past 3 months by level and ownership of health facility. Overall, provision of uterotonics was the most commonly performed function in wholly $96.8 \%$ of all obstetric care facilities. Assisted vaginal delivery $(17.2 \%)$ and evacuation of retained products of conception $(30.4 \%)$ were the least available services in past three months. Three quarters (76.1\%) of hospitals and $15.1 \%$ of health centres performed Cesarean section in past three months. Of all the 880 hospitals and health centres, 248 (28.2\%) facilities provided both Cesarean section and blood transfusion in the past three months. Only $130(14.8 \%)$ of all the 880 hospitals and health 
centres provided all the 9 EmONC functions (ie qualified as CEmONC facilities) including 95 (39.1\%) of hospitals. Across all the 9 EmONC functions, private facilities performed above the National average.

Since facilities could have failed to perform EmONC functions due to the lack of patients in need of specific services, the analyses in Table 2 exclude facilities that lacked indicated cases during the evaluation period of three months. Among facilities that did not perform functions despite of availability of indicated obstetric complications, lack of training was the most frequent reason for not performing assisted vaginal delivery (98.0\%) and evacuation of products of conception $(90.8 \%)$. Likewise policy issues that restrict performance of CEmONC functions were the main reason for failure to provide Caesarean section and blood transfusion. Nevertheless, overall lack of supplies equipment and drugs $(59.2 \%)$ and training issues $(47 \%)$ were the leading reasons for non-performance of the 7 basic EmONC functions in the presence of indicated obstetric cases.

Table 2. Number of facilities that did not provide signal functions when indicated and the given reasons for non provision.

\begin{tabular}{|c|c|c|c|c|c|c|c|}
\hline \multirow[b]{2}{*}{ Functions } & \multicolumn{4}{|c|}{ Number of Facilities that: } & \multicolumn{3}{|c|}{$\begin{array}{l}\text { \% Facilities giving reasons for not providing an } \\
\text { indicated function }\end{array}$} \\
\hline & $\begin{array}{l}\text { Did not } \\
\text { Provide } \\
\text { function in } \\
\text { last } 3 \text { months }\end{array}$ & $\begin{array}{l}\text { Did not provide } \\
\text { function because } \\
\text { there was no } \\
\text { indication }\end{array}$ & $\begin{array}{l}\text { Did not provide } \\
\text { function } \\
\text { although } \\
\text { indicated }\end{array}$ & $\begin{array}{l}\text { Training } \\
\text { issues }\end{array}$ & $\begin{array}{l}\text { Lack of } \\
\text { Supplies, } \\
\text { equipment, } \\
\text { drugs }\end{array}$ & $\begin{array}{l}\text { Management } \\
\text { issues that } \\
\text { restrict } \\
\text { providers }\end{array}$ & $\begin{array}{l}\text { Policy issues } \\
\text { restricting } \\
\text { function provision }\end{array}$ \\
\hline Inj. antibiotics & 689 & 157 & 532 & 12.0 & 21.8 & 4.5 & 2.4 \\
\hline Uterotonics & 77 & 45 & 32 & 21.9 & 96.9 & 12.5 & 3.1 \\
\hline Manual removal of placenta & 1148 & 393 & 755 & 44.5 & 30.2 & 6.8 & 4.4 \\
\hline Neonatal resuscitation & 510 & 210 & 300 & 38.0 & 57.3 & 9.3 & 6.0 \\
\hline Parenteral anticonvulsants & 1135 & 313 & 822 & 23.5 & 27.6 & 6.0 & 3.3 \\
\hline Removal of retained products & 1675 & 911 & 764 & 90.8 & 84.6 & 19.6 & 17.7 \\
\hline Assisted vaginal delivery & 1988 & 1107 & 881 & 98.0 & 95.7 & 26.0 & 26.0 \\
\hline Cesarean delivery* & 599 & 360 & 239 & 41.8 & 59.4 & 48.1 & 80.3 \\
\hline Blood transfusion* & 617 & 372 & 245 & 30.2 & 57.6 & 40.4 & 78.8 \\
\hline
\end{tabular}

* Only hospitals and Health centres were considered because dispensaries are not entitled to provide these functions.

\subsection{EmONC indicators}

The distribution of EmONC indicators by region is shown in Table 3. Overall, $21.5 \%$ of direct obstetric complications were managed in obstetric care facilities (the National level Met Need for EmONC) which are much below the ideal $100 \%$ according to United Nations (UN) benchmark. The National Caesarean section rate was $5.6 \%$ which is within the UN benchmark of 5-15\%. However, wide variations in Caesarean section rates were encountered across regions.
There were 68 obstetric care facilities per 500,000 population in Tanzania Mainland, with only 7/500,000 population providing all the $7 \mathrm{BEmOC}$ functions in past 3 months. This figure is above the minimum recommended UN benchmark of 5 per 500,000 population. Ten out of 25 regions (equivalent to $40 \%$ ) had attained or exceeded the international benchmark of 5 EmONC facilities per 500,000 population.

Table 3. Distribution of some indicators of EmONC by region.

\begin{tabular}{|c|c|c|c|c|c|c|}
\hline Region & $\begin{array}{l}\text { Met Need for } \\
\text { EmONC }\end{array}$ & $\begin{array}{l}\text { Obstetric care facilities } \\
\text { per } 500,000 \text { population }\end{array}$ & $\begin{array}{l}\text { Institution } \\
\text { delivery }(\%)\end{array}$ & $\begin{array}{l}\text { Institutional Deaths } \\
\text { per } 100,000 \text { deliveries }\end{array}$ & $\begin{array}{l}\text { BEmoNe per } \\
500,000 \text { population }\end{array}$ & $\begin{array}{l}\text { Annual Cesarean } \\
\text { section (\%) }\end{array}$ \\
\hline Arusha & 26.6 & 58 & 69 & 168 & 5 & 10.9 \\
\hline Dar es Salaam & 33 & 16 & 98 & 62 & 3.7 & 13.3 \\
\hline Dodoma & 10.3 & 73 & 73 & 115 & 2.2 & 6.5 \\
\hline Iringa & 15 & 60 & 77 & 301 & 5.8 & 9.6 \\
\hline Katavi & 9.6 & 55 & 68 & 346 & 4.4 & 1.7 \\
\hline Kilimanjaro & 30.8 & 76 & 82 & 204 & 4.3 & 9.6 \\
\hline Lindi & 38.3 & 121 & 102 & 331 & 6.4 & 7.2 \\
\hline Manyara & 12.3 & 51 & 54 & 169 & 1.1 & 8.9 \\
\hline Mbeya & 21.8 & 69 & 93 & 91 & 1.1 & 8.9 \\
\hline Morogoro & 24.5 & 63 & 84 & 120 & 4.3 & 7.6 \\
\hline Mtwara & 27.6 & 75 & 92 & 245 & 6.3 & 7.6 \\
\hline Njombe & 2.7 & 150 & 110 & 426 & 11.4 & 19.3 \\
\hline Pwani & 30.2 & 109 & 166 & 255 & 10 & 10.5 \\
\hline Rukwa & 2.2 & 95 & 84 & 191 & 1.5 & 0.9 \\
\hline Ruvuma & 49.5 & 74 & 93 & 197 & 5.1 & 14.3 \\
\hline Singida & 24.7 & 71 & 68 & 152 & 2.2 & 5.9 \\
\hline Tanga & 11.5 & 74 & 66 & 118 & 2.7 & 5.4 \\
\hline Kagera & 21 & 53 & 63 & 92 & 5.9 & 3 \\
\hline Geita & 6.7 & 33 & 51 & 101 & 4.3 & 0.1 \\
\hline Mwanza & 21.7 & 44 & 72 & 75 & 3.6 & 3 \\
\hline
\end{tabular}




\begin{tabular}{lllllll}
\hline Region & $\begin{array}{l}\text { Met Need for } \\
\text { EmONC }\end{array}$ & $\begin{array}{l}\text { Obstetric care facilities } \\
\text { per 500,000 population }\end{array}$ & $\begin{array}{l}\text { Institution } \\
\text { delivery (\%) }\end{array}$ & $\begin{array}{l}\text { Institutional Deaths } \\
\text { per 100,000 deliveries }\end{array}$ & $\begin{array}{l}\text { BEmoNc per } \\
\mathbf{5 0 0 , 0 0 0} \text { population }\end{array}$ & $\begin{array}{l}\text { Annual Cesarean } \\
\text { section (\%) }\end{array}$ \\
\hline Mara & 46.1 & 77 & 107 & 117 & 8 & 1.4 \\
Shinyanga & 34.4 & 52 & 82 & 148 & 6.8 & 1.4 \\
Simiyu & 7.6 & 48 & 46 & 121 & 4.3 & 0.3 \\
Tabora & 9.5 & 56 & 86 & 88 & 3.7 & 1.6 \\
Kigoma & 19.5 & 37 & 61 & 97 & 3.5 & 0.9 \\
National & 21.5 & 67.6 & 79 & 173.2 & 7.0 & 5.6 \\
\hline
\end{tabular}

Overall annual rate of institutional delivery was $79 \%$ with four regions namely, Pwani, Lindi, Njombe and Mara exceeding 100\% institutional birth rate (Table 3). Figure 1, shows the proportion of available CEmONC facilities relative to what would be ideal by UN standards according to regional population. Figure 1, shows that 19 regions $(76 \%)$ had either reached or exceeded the international threshold of at least $1 \mathrm{CEmONC}$ facility per 500,000 population.

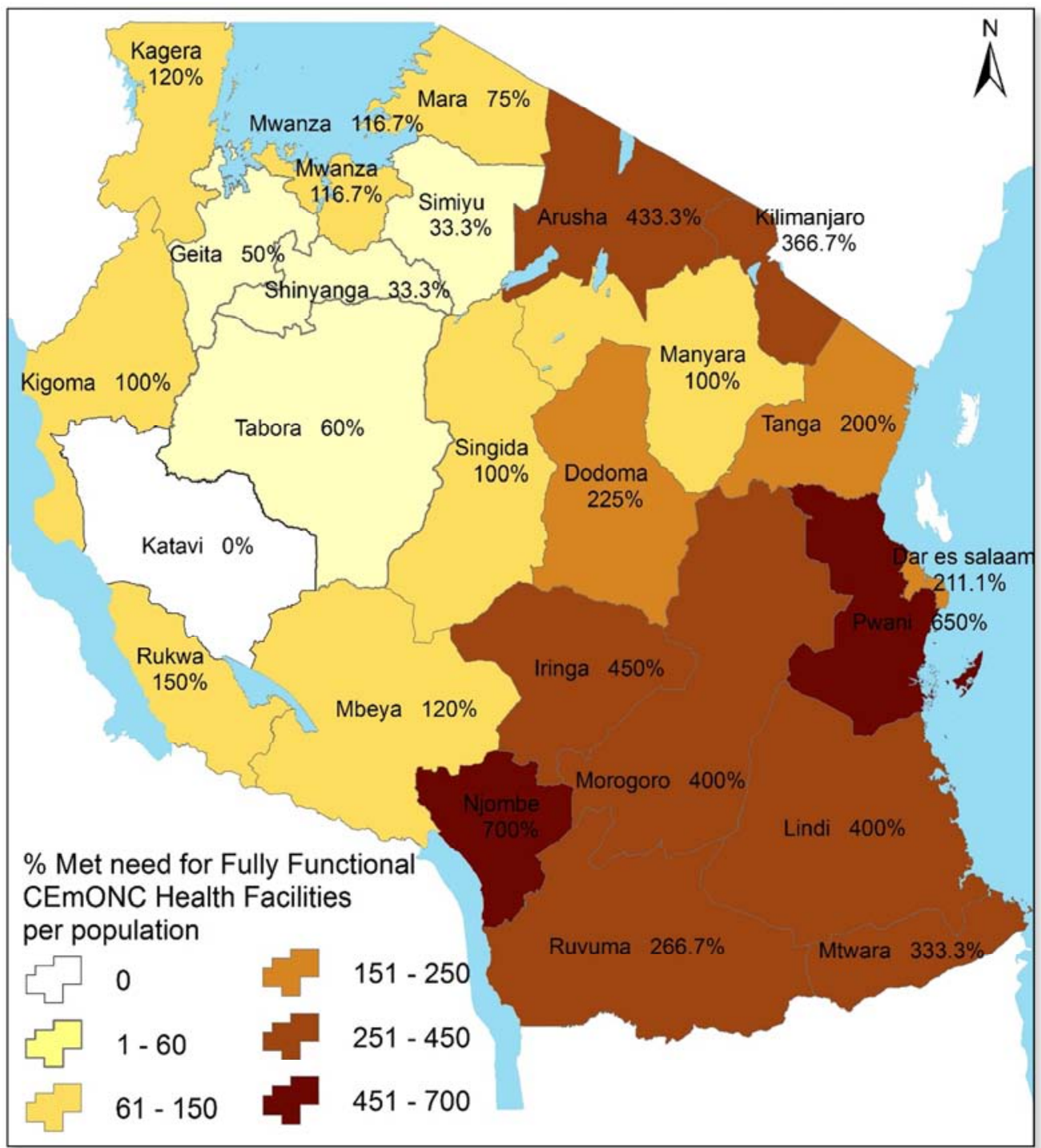

Figure 1. Proportion of available CEmONC facilities against UN benchmark per region.

\subsection{Correlation Analysis}

Table 4 is the correlation matrix for data in Table 3. An increase in Obstetric care facilities per 500,000 population (i.e, Facility density) was associated with increased institutional delivery, Met need for EmONC, Cesarean section rate and institutional deaths. An increase in number of BEmONC facilities per 500,000 population was also associated with increased institutional delivery, institutional deaths and Caesarean section rate. Increased institutional delivery was associated with increased Caesarean section rate and institutional deaths. All the correlations were strong. There was an inverse correlation of Public-Private ratio with Caesarean section rate but this did not reach statistical significance $\left(\mathrm{R}^{2}=0.155, \mathrm{r}=-0.394, \mathrm{p}=0.052\right)$. 
Table 4. Pearson Correlation coefficients for EmONC indicators.

\begin{tabular}{llllll}
\hline & $\begin{array}{l}\text { Institutional delivery } \\
\text { per all births }\end{array}$ & $\begin{array}{l}\text { Institutional Deaths per } \\
\mathbf{1 0 0 , 0 0 0} \text { deliveries }\end{array}$ & $\begin{array}{l}\text { Annual Caesarean } \\
\text { section rate }\end{array}$ & $\begin{array}{l}\text { Met need for } \\
\text { EmONC }\end{array}$ & $\begin{array}{l}\text { No. of EmONC per } \\
\mathbf{5 0 0 , 0 0 0} \text { population }\end{array}$ \\
\hline $\begin{array}{l}\text { Facility density } \\
\begin{array}{l}\text { No. of EmONC per 500,000 } \\
\text { population }\end{array}\end{array}$ & $0.599^{*}$ & $0.710^{*}$ & $0.461^{* *}$ & $0.427^{*}$ & $0.534^{*}$ \\
CS rate & $0.623^{*}$ & $0.566^{*}$ & $0.509^{*}$ & & \\
\hline
\end{tabular}

${ }^{*} \mathrm{p}<0.05, * * \mathrm{p}<0.005$

\section{Discussion}

The results of this study support significant achievements so far made in EmONC delivery services in Tanzania Mainland. Among the achievements is the high obstetric care facility density (OCFD) of 68 per 500,000 population, an increased institutional delivery from $50 \%$ a decade ago and $63 \%$ five years back to the current $79 \%$ and the National level Caesarean Section rate of $5.6 \%$ up from the $5.0 \%$ which was previously reported by previous National survey (TDHS, 2010, TDHS 2015). Moreover, the observed levels of EmONC facility density of 7 facilities per 500,000 population and the $5.6 \%$ Caesarean section rate are both higher than the minimum recommended standards [2]. All these indicators were either comparable to or better than what have been recently reported for Zanzibar [22] and elsewhere in developing countries including Zambia, Malawi, Nigeria, parts of South Africa, Ghana and Afghanistan [3, 4, 7, 23-25].

Despite these impressive achievements in EmONC service availability at a National level, the distribution of EmONC indicators was not equitable across regions and facility levels. The availability of EmONC functions was inequitably distributed among regions whereby only $40 \%$ of them had attained an ideal minimum level of BEmONC. Moreover, the coverage of CEmONC services was far better than BEmONC with three quarters of the regions having attained or exceeded the ideal threshold. It is of note that most regions of the Lake and Western zones and the newly promoted regions of Geita, Simiyu and Katavi, CEmONC coverage was conspicuously the lowest. The wide discrepancy in BEmONC and CEmONC coverage is not unique for Tanzania Mainland as it is consistently reported by studies elsewhere in developing countries $[4,5,7,11,22,24-26]$. In a systematic review of the global pattern of EmONC availability by Paxton et al., it was concluded that $\mathrm{CEmONC}$ facilities are usually available to meet the minimum recommended but BEmONC facilities are consistently not available in sufficient numbers for countries with both high and moderate levels of maternal mortality [1, 27]. The observed patterns of EmONC services availability means safe maternity services are inequitably available to many women who seek such services in the health care system in some parts of the country, especially in the Lake and Western zones of the country. Future programmes and resources should be preferentially directed towards improvement of EmONC services in the most disadvantaged areas.

Overall, provision of uterotonics, neonatal resuscitation and parenteral antibiotics were the most commonly available basic EmONC functions with the rest of basic functions being consistently provided by half or less of study facilities. Overall, assisted vaginal delivery and evacuation of products of conception were the least provided EmONC functions at a National level. Regarding CEmONC functions, only a third of eligible health facilities had provided the two CEmONC functions (i.e., Caesarean section and blood transfusion) in the past three months. The provision of EmONC functions in the current study was more consistent the higher the health facility level which is in support of the findings in a study of 12 districts of South Africa where evacuation of retained products of conception, assisted vaginal delivery, and CEmONC functions were among the least performed with better EmONC services available in higher than lower level health facilities [7]. A similar pattern of low performance and inequities in EmONC function performance has been also reported in Malawi and Afghanistan [4, 25] indicating inequitable allocation of resources.

Major reasons for non-provision of EmONC services have been broadly classified under policy, management, supply and training issues $[2,7,13]$. Working along these themes we explored what EmONC functions were not performed and for what reasons. In developing countries like Tanzania where haemorrhage and abortion complications claim most maternal deaths, the lack of manual removal of placenta, manual vacuum aspiration to treat abortion complications and assistance of vaginal delivery with vacuum should contribute significantly to maternal mortality. In the current study, the three most important reasons for non provision of EmONC functions were the lack of supplies and professional training for the basic EmONC functions and policy issues that restrict service provision for Caesarean section and blood transfusion. It is therefore implicit that reassured commodity supplies, strengthening continual professional education among healthcare professionals and ending policy bottlenecks that hinder CEmONC provision and equitable allocation of resources in facilities capable of providing such services would markedly improve EmONC standards. Tanzania mainland with 68 obstetric care facilities per 500,000 population possesses a huge potential to improve on if resources can be utilized to promote the existing facilities.

Since 2007 Tanzania has embarked on construction and staffing of new health facilities that would lead to having a dispensary at every village, a Health Centre at every ward and a District Hospital at every District by 2017 under the PHSDP [14]. The current study sought to establish if 
increased OCFD would positively correlate with facility utilisation among other standard EmONC indicators. In support of the PHSDP strategy, a strong positive correlation between increased OCFD and institutional delivery was established. The increased institutional delivery rate from $50 \%$ in the past decade to the current $79 \%$ was impressive albeit this rise falls short of reaching the $90 \%$ National target which was set for 2015[28]. This increased utilisation could be at least partly explained by the minimized geographical distance between obstetric care facilities and communities, a factor which has been shown to promote institutional delivery elsewhere [29, 30]. Nevertheless, a wide variation in rates of institutional delivery across regions was observed from as low as $46 \%$ in Simiyu to above $100 \%$ in four regions of Mara, Pwani, Njombe and Lindi. The discrepancy in regional rates of institutional delivery is a reflection of the differences in the volume of maternity services provided. Institutional delivery more than $100 \%$ can indirectly reflect poor service availability in the regional neighbourhood forcing women to seek services outside their catchment, a situation that might lead to overcrowding of facilities in the host facilities as a consequence. In support to this connotation, all the regions with excessive institutional delivery (above 100\%), also had the highest OCFD in the country which would be the attracting force for immigration of delivering mothers from the neighbourhood.

PHSDP could have improved the availability of obstetric care facilities in Tanzania Mainland but it seems unlikely that the existed staffing shortage of $56.4 \%$ of health care personnel at the onset of the program has been sufficiently improved [14]. This health personnel shortage adding to the established inconsistencies in availability of commodities and professional training must have negatively impacted on the quality of care. As a result, although OCFD was positively correlated with institutional delivery and Met Need for EmONC and Cesarean section rate it was also associated with increased institutional deaths. Thus, the increased institutional deaths could be partly explained by suboptimal quality of care and the increased number of women seeking medical attention due to direct obstetric complications leading to severely sick women increasingly more deaths occurring in facilities rather than in communities.

A low Met need for EmONC is an indication that still many direct obstetric complications are not managed in obstetric care facilities. The National met need of $21.5 \%$ in the current study is lower than the average Global Met need of $45 \%$ but just above the $21 \%$ for the low income countries that ranges $12 \%$ to $31 \%$ [9]. In the current study, we observed in-country variation among regions where Met Need ranged from $2.2 \%$ in Rukwa to $49.5 \%$ in Ruvuma. This range also accommodates the 33\% Met need for Zanzibar which was recently reported in that part of the United Republic of Tanzania [22]. In the estimation of Met need for the current study we adopted a $15 \%$ rate of direct obstetric complications among live births. This estimate has been held by World Health Organization (WHO) as reasonable based on a series of studies conducted in India and the United
States of America (USA) [9, 31-33]. However, global adoption of the $15 \%$ figure has been criticized for not being reasonable in all settings owing to variations in the prevalence of various diseases, nutrition and age at first pregnancy [9, 34, 35]. Thus, the observed discrepancy between Institutional delivery and Met need in the current study could be explained at least partly by over diagnosis of serious direct obstetric complications in the community, poor documentation of complications in facilities or both.

Several limitations of the study design warrant to be discussed here. In a systematic review by Holmer et al, the global Met need was correlated with improved care by skilled birth attendance and inversely correlated with maternal deaths [9]. The current study further indicates that Met need strongly correlates with increased population Caesarean section rate, a proxy to improved quality care. As a result, where quality of service is questionable, many women with serious direct obstetric complications will not seek treatment in facilities. Nevertheless, there is need to understand other factors outside the healthcare system and address them along with improvement of quality services. Factors outside the health system were not sufficiently explored by this study design.

This study was based on the EmOC framework that has been criticised for not adequately capturing the quality of care received or the general condition of the patients at admission [9]. In real situation initial pre-referral care given in obstetric care facilities that do not qualify as EmONC could be even more important for life saving than the care given in EmONC facility. With this knowledge, we studied private and public obstetric care facilities in addition to designated EmONC facilities in order to give a more complete picture of obstetric care in Tanzania Mainland. However, the reliance on recorded hospital data and population estimates may have exposed this study to the inherent problems of documentation and reporting often leading to underreporting of complications. Nevertheless, enquiry about events that happened within the past 3 months was done to improve memorisation and minimize data loss [10] in efforts to mitigate this limitation.

The estimation of obstetric complications using $15 \%$ of live births as a population estimate has been supported by WHO, but questioned by other researchers [10, 35]. Nevertheless, this study has adopted this standard estimate to facilitate comparability with other international data with a risk of over or under-estimating the absolute number of direct obstetric complications that are actually happening in Tanzania Mainland. While the absolute numbers of direct obstetric complications could substantially differ from the actual, the value of our results as baseline for future followup of complication trends and comparability with other international data is enhanced owing to the wide international use of the indicator.

Despite the above limitations, this study provides a national wide current data on EmONC service utilisation and correlates of EmONC indicators that were unavailable before for Tanzania Mainland. The findings will inform policy, 
program managers and researchers on strategies aimed at improving EmONC services in Tanzania Mainland.

\section{Conclusion}

Improved OCFD is strongly correlated with improved institutional delivery; Caesarean section rate and met need for EmONC but inequitable distribution of EmONC services especially in the newly promoted regions in Lake and Western zones and the low quality of care remain the major challenges.

\section{Acknowledgements}

Special appreciation goes to people who in one way or the other contributed to the research process. Particularly would wish to acknowledge the valuable inputs from Dr. Ahmad Makwani, Dr. Kohleth Winani, Dr. Mery Azayo and Mr. Ernest Kihinga (Ministry of Health Community Development, Gender, Elderly and Children), Mr Samwel Kawa and Ms, Aurelia Kokulamuka (National Bureau of Statistics) for providing vital statistical data for this report. Dr Rutasha Dadi (UNFPA), Dr. Theopista John (WHO), Dr. Asia Khusein (UNICEF), Regional and District Medical Officers, Research Assistants and others who in one way or the other made this study a success.

\section{References}

[1] Paxton A, Maine D, Freedman L, Fry D, Lobis S: The evidence for emergency obstetric care. Int J Gynaecol Obstet 2005; 88(2):181-193.

[2] AMDD: Averting Maternal Death and Disability Program (AMDD). Needs Assessment of Emergency Obstetric and Newborn Care (EmONC): Facilita tor's Guide. In. Edited by AMDD. New York: Columbia University; 2009.

[3] Bosomprah S, Tatem AJ, Dotse-Gborgbortsi W, Aboagye P, Matthews Z: Spatial distribution of emergency obstetric and newborn care services in Ghana: Using the evidence to plan interventions. Int J Gynaecol Obstet 2016; 132(1):130-134.

[4] Kongnyuy EJ, Hofman J, Mlava G, Mhango C, van den Broek $\mathrm{N}$ : Availability, utilisation and quality of basic and comprehensive emergency obstetric care services in Malawi. Matern Child Health J 2009; 13(5):687-694.

[5] Ng'anjo PS, Fylkesnes K, Moland KM, Byskov J, Kiserud T: Rural-Urban Inequity in Unmet Obstetric Needs and Functionality of Emergency Obstetric Care Services in a Zambian District. PLoS ONE Editor: Hamid Reza Baradaran, Iran University of 2016, 11(1).

[6] Otolorin E, Gomez P, Currie S, Thapa K, Dao B: Essential basic and emergency obstetric and newborn care: from education and training to service delivery and quality of care. Int J Gynaecol Obstet 2015; 130 Supp1 2:S46-53.

[7] Pattinson RC, Makin JD, Pillay Y, Van den Broek N, Moodley $\mathrm{J}$ : Basic and comprehensive emergency obstetric and neonatal care in 12 South African health districts. S Afr Med J 2015; 105(4):256-260.
[8] Utz B, Zafar S, Arshad N, Kana T, Gopalakrishnan S: Status of emergency obstetric care in four districts of Punjab, Pakistan - results of a baseline assessment. J Pak Med Assoc 2015; 65(5):480-485.

[9] Holmer H, Oyerinde K, Meara JG, Gillies R, Liljestrand J, Hagander L: The global met need for emergency obstetric care: a systematic review. Bjog 2015; 122(2):183-189.

[10] WHO: Monitoring Emergency Obstetric Care: A Handbook. Geneva: World Health Organization; 2009.

[11] Abegunde D, Kabo IA, Sambisa W, Akomolafe T, Orobaton N, Abdulkarim M, Sadauki H: Availability, utilization, and quality of emergency obstetric care services in Bauchi State, Nigeria. Int J Gynaecol Obstet 2015; 128(3):251-255.

[12] Ansari MS, Manzoor R, Siddiqui N, Ahmed AM: Access to comprehensive emergency obstetric and newborn care facilities in three rural districts of Sindh province, Pakistan. Health Res Policy Syst 2015; 13 Suppl 1:55.

[13] Chi PC, Bulage P, Urdal H, Sundby J: Barriers in the Delivery of Emergency Obstetric and Neonatal Care in Post-Conflict Africa: Qualitative Case Studies of Burundi and Northern Uganda. PLoS One 2015; 10(9):e139120.

[14] MOHSW: Human Resource for Health and Social Welfare Strategic Plan 2014 - 2019. In. Edited by Welfare MOHSW. Dar es Salaam: Ministry of Health and Social Welfare; 2014.

[15] Schneeberger C, Mathai M: Emergency obstetric care: Making the impossible possible through task shifting. Int J Gynaecol Obstet 2015; 131 Suppl 1:S6-9.

[16] Sikder SS, Labrique AB, Ali H, Hanif AA, Klemm RD, Mehra S, West KP, Jr., Christian P: Availability of emergency obstetric care (EmOC) among public and private health facilities in rural northwest Bangladesh. BMC Public Health $2015 ; 15: 36$.

[17] Ueno E, Adegoke AA, Masenga G, Fimbo J, Msuya SE: Skilled birth attendants in Tanzania: a descriptive study of cadres and emergency obstetric care signal functions performed. Matern Child Health J 2015; 19(1):155-169.

[18] Vora KS, Yasobant S, Patel A, Upadhyay A, Mavalankar DV: Has Chiranjeevi Yojana changed the geographic availability of free comprehensive emergency obstetric care services in Gujarat, India? Glob Health Action 2015; 8:28977.

[19] Khan KS, Wojdyla D, Say L, Gulmezoglu AM, Van Look PF: WHO analysis of causes of maternal death: a systematic review. Lancet 2006; 367(9516):1066-1074.

[20] WHO, UNICEF: Countdown to 2015 Decade Report (20002010): Taking Stock of Maternal, Newborn and Child Survival. In. Geneva: World Health Organization; 2010.

[21] Cohen J: Statistical power analysis for the behavioral sciences, $2^{\text {nd }}$ edn. Hillsdale, NJ: Lawrence Erlbaum Associates; 1988.

[22] Fakih B, Nofly AA, Ali AO, Mkopi A, Hassan A, Ali AM, Ramsey K, Kabuteni TJ, Mbaruku G, Mrisho M: The status of maternal and newborn health care services in Zanzibar. $B M C$ Pregnancy Childbirth 2016; 16(1):134.

[23] Eniola A. Bamgboye EA, Akindele O. Adebiyi, A. O., Fatiregun, A. A.: Assessment of Emergency Obstetric Care Services in Ibadan-Ibarapa Health Zone, Oyo State, Nigeria. African Journal of Reproductive Health 2016; 20(1):88-97. 
[24] Gabrysch S, Simushi V, Campbell OM: Availability and distribution of, and geographic access to emergency obstetric care in Zambia. Int J Gynaecol Obstet 2011; 114(2):174-179.

[25] Kim YM, Zainullah P, Mungia J, Tappis H, Bartlett L, Zaka $\mathrm{N}$ : Availability and quality of emergency obstetric and neonatal care services in Afghanistan. Int J Gynaecol Obstet 2012, 116(3):192-196.

[26] Olsen OE, Ndeki S, Norheim OF: Availability, distribution and use of emergency obstetric care in northern Tanzania. Health Policy Plan 2005; 20(3):167-175.

[27] Paxton A, Bailey P, Lobis S, Fry D: Global patterns in availability of emergency obstetric care. Int J Gynaecol Obstet 2006; 93(3):300-307.

[28] MOHSW: The National Road Map Strategic Plan to Improve Reproductive, Maternal, Newborn, Child \& Adolescent Health in Tanzania (2016 - 2020). In: One Plan II. Dar es Salaam; 2015.

[29] Yasobant S, Vora KS, Shewade HD, Annerstedt KS, Isaakidis P, Mavalankar DV, Dholakia NB, De Costa A: Utilization of the state led public private partnership program "Chiranjeevi Yojana" to promote facility births in Gujarat, India: a cross sectional community based study. BMC Health Serv Res 2016; 16:266.
[30] Saxena D, Vangani R, Mavalankar DV, Thomsen S: Inequity in maternal health care service utilization in Gujarat: analyses of district-level health survey data. Glob Health Action 2013; $6: 1-9$.

[31] Bennett TA, Kotelchuck M, Cox CE, Tucker MJ, Nadeau DA: Pregnancy-associated hospitalizations in the United States in 1991 and 1992: a comprehensive view of maternal morbidity. Am J Obstet Gynecol 1998; 178(2):346-354.

[32] Bang RA, Bang AT, Reddy MH, Deshmukh MD, Baitule SB, Filippi V: Maternal morbidity during labour and the puerperium in rural homes and the need for medical attention: A prospective observational study in Gadchiroli, India. Bjog 2004; 111(3):231-238.

[33] McCord C, Premkumar R, Arole S, Arole R: Efficient and effective emergency obstetric care in a rural Indian community where most deliveries are at home. Int J Gynaecol Obstet 2001; 75(3):297-307; discussion 308-299.

[34] Ronsmans C, Campbell OM, McDermott J, Koblinsky M: Questioning the indicators of need for obstetric care. Bull World Health Organ 2002; 80(4):317-324.

[35] Paxton A, Bailey P, Lobis S: The United Nations Process Indicators for emergency obstetric care: Reflections based on a decade of experience. Int J Gynaecol Obstet 2006; 95(2):192-208. 